\title{
EL BOOM INMOBILIARIO EN ASTURIAS. REFLEXIONES SOBRE SU DESARROLLO Y CONSECUENCIAS
}

\author{
Asturias housing boom. remarks on its development and \\ consequences
}

\author{
Marcos Ortega Montequín*
}

Recibido: 24/04/ 2012

Aceptado: 5/06/2012

\begin{abstract}
Resumen: Entre 1998 y 2007 se desarrolló un boom inmobiliario en España. Si bien en Asturias sus efectos no han sido tan destacados como en otras regiones, su repercusión resulta notable, con un crecimiento del parque residencial superior al demográfico y a las necesidades habitacionales del mismo; esto ha conllevado la presencia de un excedente de viviendas así como la transformación, en mayor o menor medida, de numerosas entidades de población.

Palabras clave: Boom inmobiliario, burbuja, vivienda, territorio, población, hogar.

Abstract: Between 1998 and 2007 there was a housing boom in Spain. Even though in Asturias its effects have not been as prominent as in other regions, its impact has been substantial, with a growth in housing greater than in population and its dweling needs. This has led to the existence of a house stock as well as the transformation, to a greater or lesser extent, of numerous population entities.

Key words: Housing boom, housing bubble, dwelling, territory, population, home.
\end{abstract}

\section{INTRODUCCIÓN}

Entre 1998 y 2007 se desarrolló en España un momento de apogeo del sector de la construcción, fundamentalmente sustentado por la creación de viviendas nuevas que, popular y periodísticamente, ha recibido el nombre de boom de la construcción, o del ladrillo, o inmobiliario. El término, a pesar de su voz inglesa, resulta muy descriptivo y adecuado, pues el propio diccionario de la Real Academia Española lo define como "Éxito o auge repentino de algo"1. Paralelamente, también se habló de la burbuja ${ }^{2}$ inmobiliaria, en un discurso más enfocado hacia los riesgos de una caída repentina del sector, lo que finalmente se produjo.

Este importante crecimiento del parque residencial no tuvo una relación directa con las necesidades habitacionales existentes para el momento: un bajo precio del dinero, lo que favoreció el crédito hipotecario (así como que se elongasen los periodos de amortización), y una escalada continuada en los precios de los inmuebles contribuyeron a que la vivienda se transformase en un producto destinado a la inversión en su acepción más financiera, lo que conlleva que una parte importante de las compra-ventas (incluida la construcción, que

\footnotetext{
* Profesional independiente / Grupo de trabajo [pro]yecta. El presente artículo está basado en la investigación realizada en la asignatura Trabajo Fin de Máster dentro del itinerario de Geografía del Máster universitario en métodos y técnicas avanzadas de investigación histórica, artística y geográfica, impartido por la UNED, realizado bajo la dirección del profesor José Miguel Santos Preciado.

${ }^{1}$ DRAE, consultado en Web.

2 Burbuja (económica): Término de origen bursátil, es un fenómeno que se presenta toda vez que se «negocia altos volúmenes a precios que difieren considerablemente de los valores intrínsecos". Gabriel Tortella (2008) lo explica del siguiente modo: "si las acciones suben en Bolsa, los ahorradores suponen que las subidas van a continuar, y compran; las compras hacen subir las cotizaciones, por lo que las expectativas se cumplen y aumentan los ahorradores deseosos de comprar. Las cotizaciones siguen subiendo; pero llega un momento en que los dividendos resultan insignificantes ante el precio de las acciones: Ios ahorradores dejan de comprar y las cotizaciones caen. Los accionistas suponen que van a seguir cayendo, y venden, lo cual hace que, en efecto, sigan cayendo".
} 
no es más que prever una venta de nueva planta) hayan sido operaciones comerciales con la esperanza de obtener beneficios basados en las variaciones de los precios.

Este periodo definido es coincidente con la vigencia de la Ley 6/1998, de 13 de abril, sobre el régimen del suelo y valoraciones o ley del suelo de 1998, cuyo mayor postulado es la absoluta liberalización del suelo, lo que han llamado "el todo urbanizable" y lo que supone haber sido el motivo de desarrollarse el boom inmobiliario. Sin embargo, no parece objetivo culpar a esta ley de todo lo acaecido (a pesar de su peso específico), pues parece que el espíritu de la misma ya estaba imbuido en la legislación anterior, puesto que la tendencia de la construcción ya conllevaba un importante crecimiento y, además, ya desde 1998 el número de viviendas iniciadas se dispara, lo que resulta administrativa y físicamente imposible de atribuir a la citada ley.

Si bien en Asturias apenas se levantaron el 1,8\% de las viviendas del periodo aludido y con una intensidad muy inferior a las regiones de mayor fervor, las consecuencias han sido más que palpables en numerosos núcleos de población caso de las principales ciudades, villas y núcleos rurales.

\section{EL BOOM ESPAÑOL COMO CONTEXTO}

\subsection{El auge constructivo}

El desarrollo del boom inmobiliario se enmarca en el periodo 1998-2007 en función de diversos criterios tales como el número de viviendas libres iniciadas, su variación interanual y la proporción de viviendas protegidas iniciadas. No obstante, como se puede apreciar, todos estos criterios pasan por las viviendas iniciadas, que son las que mejor representan las expectativas de negocio que alimentan el proceso. No obstante, tal y como se puede percibir en la figura 1, el proceso de construcción es lo suficientemente $\operatorname{largo}^{3}$ como para que sus efectos se prolonguen hasta 2009.

Figura 1: Viviendas iniciadas y terminadas en España.

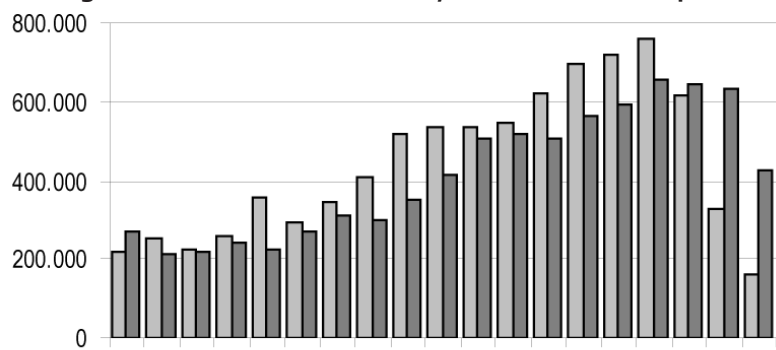

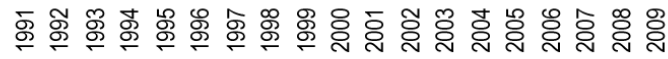

$\square$ Viviendas iniciadas $\square$ Viviendas terminadas

Fuente: Ministerio de Fomento4. Elaboración propia.
Figura 2: Viviendas terminadas entre 1998 y 2009 en España.

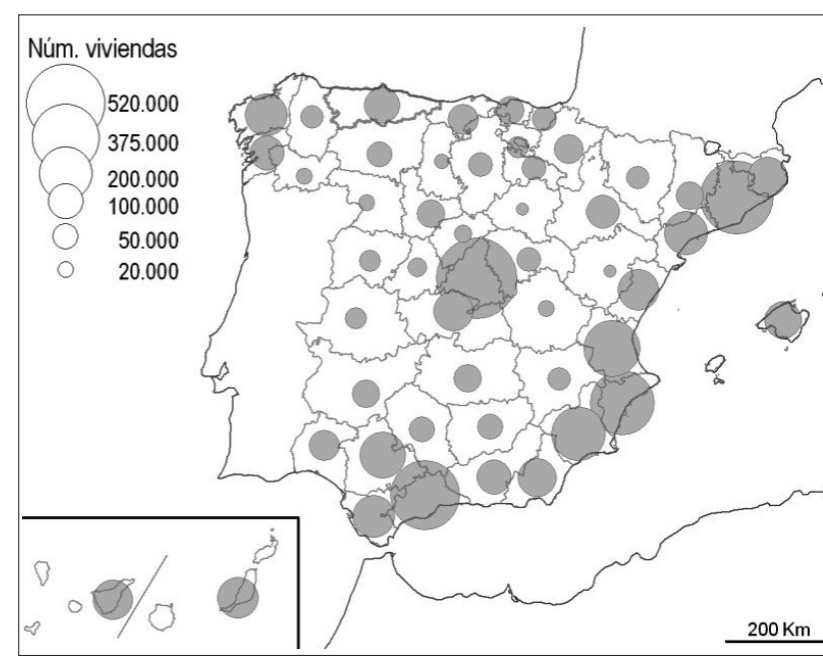

Fuente: Ministerio de Fomento. Elaboración propia.

Según las estimaciones del Ministerio de Fomento, en este periodo el parque residencial español pasó de 19.813.982 viviendas en 1998 a 25.557.237 en 2009, lo que supone un incremento de 5.743 .255 viviendas, es decir, de casi el 30\% en tan sólo 11 años. Sin embargo, como se puede apreciar en la figura 2 este incremento no ha sido homogéneo en todo el país, centrándose fundamentalmente en dos ámbitos: Madrid y su periferia, por un lado, con tendencia a la vivienda principal y que supone el 13\% del total nacional; y la costa mediterránea, con un claro enfoque hacia la residencia vacacional (viviendas secundarias) y que representa el $45 \%$ del total nacional con casi dos millones y medio de nuevas viviendas. Si a estos espacios se añadiesen las viviendas levantadas en las provincias insulares, en conjunto representarian el 65\% de las viviendas edificadas durante el boom.

Asturias, por su lado, con poco más de cien mil unidades sólo representa el 1,8\% de las nuevas viviendas del boom inmobiliario nacional.

Sin embargo, el crecimiento del parque residencial, por sí mismo, no puede considerarse como un indicador único del boom, sino que éste debe relacionarse con otros, siendo el volumen de la población el que mejor refleja el fenómeno. En este sentido, y a tenor de lo que indica la figura 3 , el crecimiento de parque residencial ha resultado ser muy superior al demográfico a pesar de los casi siete millones de habitantes ganados.

${ }^{3}$ De dos años como promedio entre vivienda iniciada y vivienda terminada, según los datos facilitados por el Estudio sobre la Oferta de Viviendas de Nueva Construcción" del Ministerio de Fomento.

${ }^{4}$ Las viviendas iniciadas suponen la suma de las viviendas libres iniciadas y las calificaciones provisionales de vivienda protegida; las terminadas representan la suma de las viviendas libres terminadas y las calificaciones definitivas de viviendas protegidas. 
Figura 3: Evolución relativa de población y vivienda en España. 1998=100.

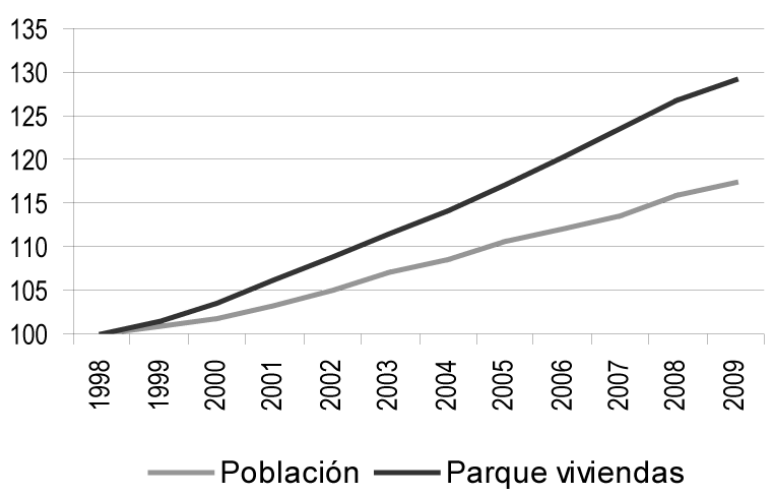

Fuente: Ministerio de Fomento e Instituto Nacional de Estadística. Elaboración propia.

Todo ello ha supuesto que se haya pasado de 507 viviendas por cada mil habitantes en 1998, cifra ya de por si elevada 5 , a 546, la mayor presente en la Unión Europea. No obstante, cabe mencionar que al relacionar dos variables, este indicador depende tanto de la dinámica inmobiliaria como de la demográfica; así se da el caso que las provincias que han registrado un mayor crecimiento se corresponden con aquellas que han sufrido pérdida de población, mientras que los espacios de mayor fervor constructivo han contado con una menor repercusión o incluso han visto reducida esta cifra. Esto derivaría del hecho de que las provincias con un mayor auge en la construcción han sido centros de recepción de migraciones, especialmente internacionales.

Asturias, por su lado, durante el periodo analizado apenas ha variado su población, con un incremento de apenas unas décimas porcentuales, lo que unido a las nuevas viviendas ha conllevado que pase de 474 viviendas por mil habitantes en 1998 a 567 en 2009, superando claramente el promedio nacional.

\subsection{La explosión de la burbuja}

Uno de los apelativos al fenómeno analizado es el de burbuja, en el que se denunciaba, además de una sobredimensión tanto en la construcción de viviendas como en la escalada de sus precios, el enorme riesgo económico que implicaba la especialización en un único sector que, durante el periodo señalado, vivía un gran auge. Y, en efecto, se trataba de una burbuja. Esto queda patente en la figura 1, donde se puede observar cómo desde el año de cierre del boom, 2007, el volumen de viviendas iniciadas caía en torno al 50\% anual; así, de las 617.331 viviendas iniciadas en 2007 se pasa a 328.443 en 2008 y 159.234 en 2009 . Y esta reducción se manifiesta de un modo mucho más palpable si se hace referencia sólo a las viviendas libres iniciadas, pues la proporción de las viviendas protegidas crece de un modo ostensible.

Tras el estallido de la burbuja, queda como herencia de este periodo un volumen ingente de viviendas vacías, lo que evidencia un sobredimensionamiento del parque residencial español. Así, diversas fuentes señalan diferentes valores del exceso de oferta acumulada para diversos $a_{n ̃ o s}^{6}$, pero quizás resulte más representativo el stock de viviendas nuevas terminadas sin vender que aporta el Ministerio de Fomento, que estima que se trataba de 688.000 unidades en 2009.

Figura 4: Stock de viviendas nuevas terminadas sin vender en 2009 en España.

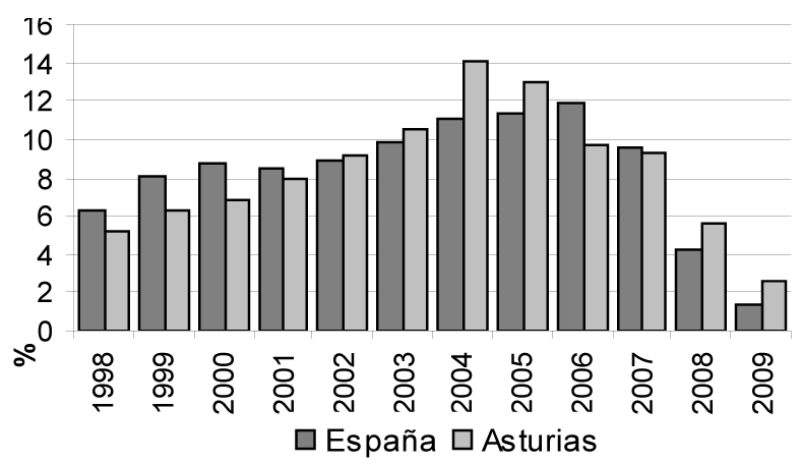

Fuente: Ministerio de Fomento. Elaboración propia.

La figura 4 evidencia que el fenómeno de las viviendas nuevas terminadas sin vender cuenta con una relación directa con la construcción; así, donde más viviendas se han levantado, mayor es el volumen del mencionado stock. No obstante, las proporciones varian sustancialmente en el caso de la costa mediterránea, pues su stock representa el 54\% del nacional. A éste cabe añadir que el 12\% le corresponde a Madrid y su periferia, asi como el $8 \%$ a las provincias insulares, lo que implica que tres cuartas partes de las viviendas nuevas terminadas $\sin$ vender se encuentran en estos ámbitos.

Asturias, por su lado, cuenta con unas 12.000 viviendas nuevas terminadas sin vender, lo que representa 1,7\% del volumen total nacional.

\section{EL BOOM INMOBILIARIO ASTURIANO}

\subsection{La producción de viviendas}

Si bien se mencionaba que las cifras de Asturias en materia de producción de nuevas viviendas resultaban relativa-

\footnotetext{
${ }^{5}$ Extrapolado a partir de restar al parque residencial de 2001 las viviendas terminadas en los años anteriores, según datos del Ministerio de Fomento.

${ }^{6} 500$ viviendas por cada mil habitantes supone la existencia de una vivienda por cada dos personas; Según THE HAGE (2010), en 2008, en la Unión Europea, además de España, sólo rebasaban esta cifra Francia, Portugal y Finlandia.
} 
mente bajas respecto de las del conjunto nacional, éstas son más que dignas de recibir el término de boom que se está empleando durante todo el artículo. Así, se pasa de 509.000 viviendas existentes en $1998^{7}$ a 614.000 en 2009 , lo que supone que en este periodo el parque residencial asturiano creció en unas 105.000 unidades, lo que representa el 17\% del total de viviendas existentes para dicho año.

Su desarrollo ha sido semejante al nacional, si bien ha contado con una mayor concentración en los años centrales del proceso y una caída más temprana de los volúmenes constructivos residenciales. De todos modos, los caracteres vienen a ser los mismos, con un crecimiento palpable de las viviendas iniciadas desde 1998, aunque en menor proporción, y un desplome en 2008 y 2009, también de menor entidad (figura $n^{\circ} 5$ ).

En cuanto a la proporción de viviendas protegidas iniciadas, se puede apreciar en la figura 6 un comportamiento análogo entre Asturias y el conjunto nacional con dos salvedades: la primera sería que Asturias partía en el inicio del boom con una proporción bastante mayor; la segunda, implica una reactivación relativa más tardía que la de España en su conjunto. De hecho, merece la pena atender al final del proceso, concretamente a la disparidad entre los valores de Asturias en 2009 respecto de sus años precedentes, pues con 3.535 viviendas protegidas iniciadas supone casi dos veces y media las iniciadas el año anterior y más de la mitad del total de viviendas iniciadas ese año, por lo que se podría hablar bien de un boom de la vivienda protegida, bien de viviendas póstumas de iniciativa pública.

Respecto de la distribución espacial de estos crecimientos, la mayor parte se condensan en el área central, donde también se aglutina la mayor parte de la población. Especialmente deben destacarse los casos de Oviedo, con 34.500 nuevas viviendas, y Gijón, con 23.500, pues entre ambos suman más de la mitad de las viviendas levantadas durante el boom. Siero, Avilés y Langreo serian otros concejos del área central con importantes desarrollos, si bien se muestran muy distantes de las dos mayores ciudades.

Por su lado, la costa oriental cuenta con un crecimiento hasta cierto punto destacado, siendo Llanes el quinto municipio respecto de crecimiento del parque residencial, mientras que en el resto de la región su repercusión resulta muy inferior (figura $n^{\circ} 7$ )

Analizando este mismo fenómeno en términos de crecimiento relativo, implica realizar una diferenciación de áreas importante (figura $n^{\circ} 8$ )

- La periferia y espacios intersticiales del triángulo formado por las tres mayores ciudades, Oviedo, Gijón y Avilés, así como el propio municipio de Oviedo cuentan con algunos de los mayores valores de crecimiento relativo. Es un área tendente hacia la vivienda principal asociadas a las ciudades citadas. Cabe mencionar que las diez mayores entidades de población del surco prelitoral (al norte y al este de Oviedo, en los municipios de Llanera, Noreña, Oviedo
Figura 5: Comparación del reparto de las viviendas iniciadas durante del boom entre Asturias y el conjunto de España.

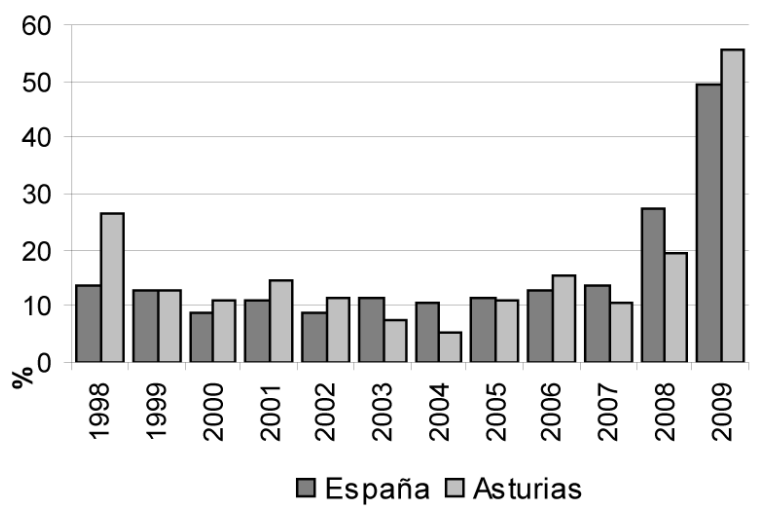

Fuente: Ministerio de Fomento ${ }^{8}$. Elaboración propia.
Figura 6: Peso relativo de las viviendas iniciadas protegidas en Asturias y España.

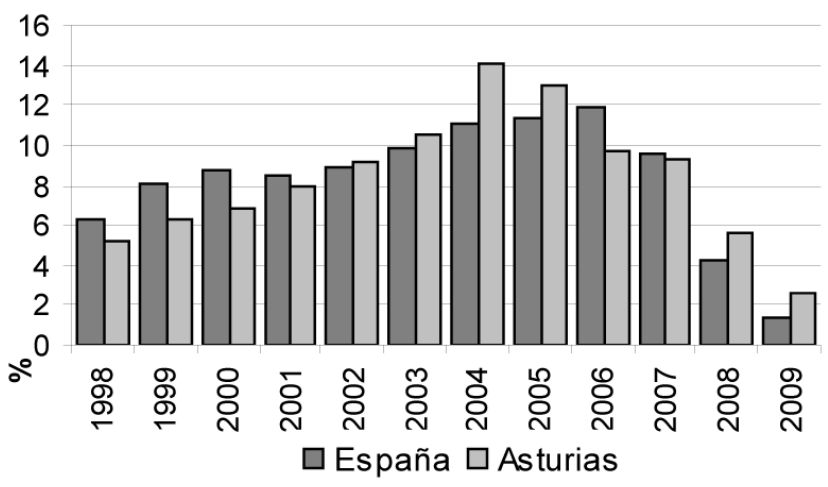

Fuente: Ministerio de Fomento. Elaboración propia.

7 Publicado en FUENTES CASTRO (2009):

Ministerio de vivienda: 1.011.000 unidades de exceso de oferta acumulado en 2007.

Colegio de registradores: 895.00 en 2007.

Encuesta sobre vivienda potencial: 1.323.000, en 2006

Encuesta de Población Activa: 1.232.000, en 2007.

PHOGUE y ECV: 1.303.000, en 2006.

${ }^{8}$ Estimado a partir de las cifras aportadas por el Censo de población y vivienda de 2001 y las viviendas terminadas aportadas por el Ministerio de Fomento.

${ }^{9}$ En viviendas protegidas el equivalente a viviendas iniciadas son las calificaciones provisionales. 
Figura 7: Distribución del crecimiento estimado del parque residencial en Asturias, 1998-2009.

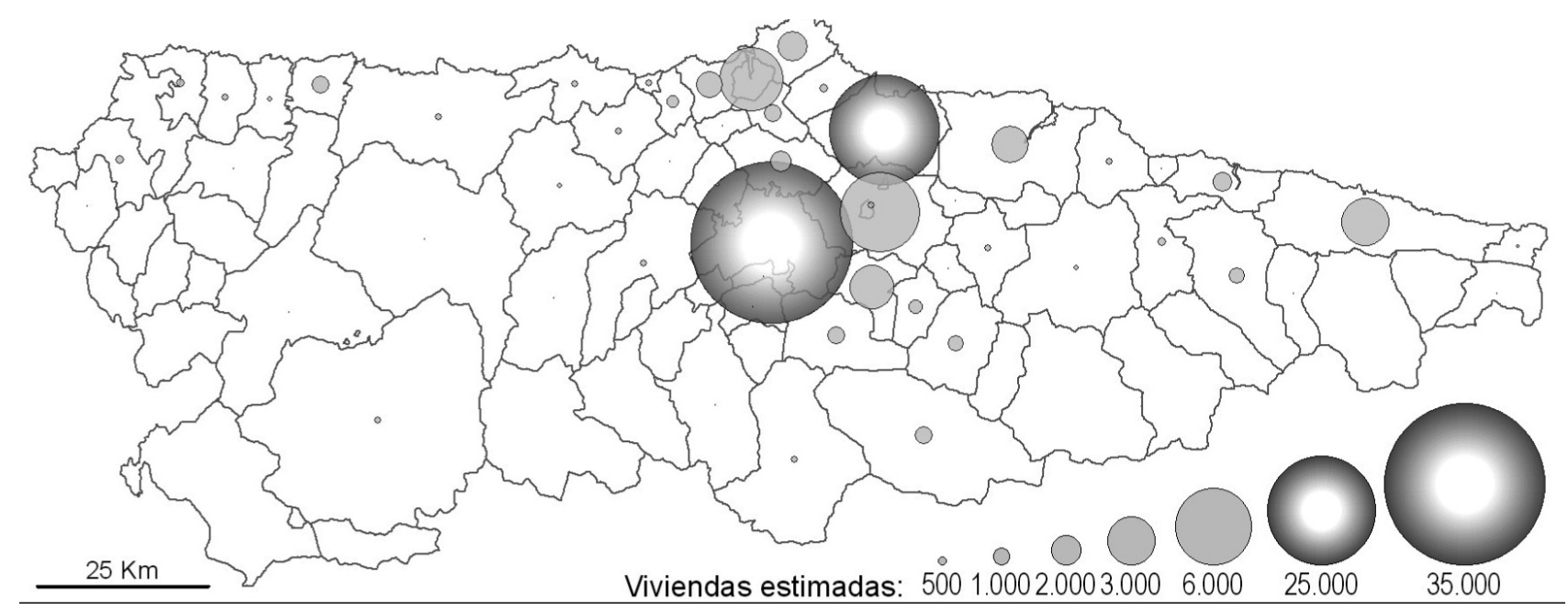

Fuente: SADEI. Elaboración propia.

Figura 8: Distribución del crecimiento estimado relativo del parque residencial en Asturias, 1998-2009.

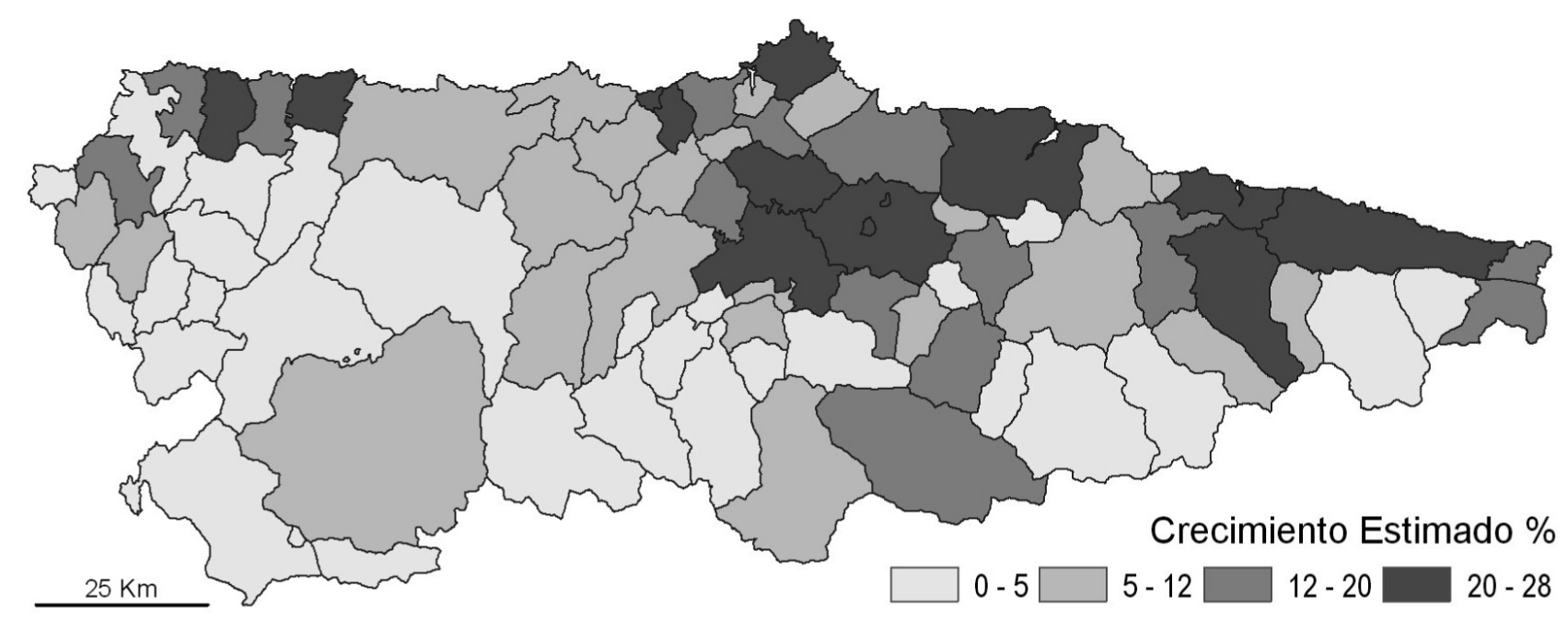

Fuente: SADEI. Elaboración propia.

y Siero) presentaron un crecimiento demográfico del 55\% entre 1996 y 2009.

- La comarca oriental, especialmente la costa y Cangas de Onís, también cuentan con un crecimiento muy destacado. No obstante, al tratarse de áreas con una gran relevancia del turismo, ha habido una tendencia importante hacia la construcción de viviendas secundarias, es decir, aquellas de las que se realiza un uso estacional y/o finisemanal.

- Otros casos de crecimientos destacados del parque de viviendas son los de El Franco, Soto del Barco y Muros del Nalón, similar al de la costa oriental (si bien los dos últimos casos cuentan con una mayor despropor- ción) y Carreño y Gozón, donde su situación próxima a Gijón y Avilés, el peso de sus plantas industriales próximas a dichas ciudades y unas villas capitales (Candás y Luanco) con cierto peso del subsector turístico, hacen que la construcción haya contado con una tendencia intermedia a los dos puntos anteriores.

- Las áreas interiores y de montaña cuentan con las menores proporciones de crecimientos residenciales.

Una clave de la construcción residencial en este periodo ha sido la proliferación de viviendas no principales, pues como se puede observar en la tabla 1 el $84 \%$ del crecimiento residencial se apoyó en este tipo de viviendas, hasta el punto 
Tabla 1: Evolución de viviendas y hogares en Asturias $^{9}$

\begin{tabular}{|l|c|c|c|c|}
\hline & 2001 & $\mathbf{2 0 0 9}$ & Crecimiento & \% nuevas viviendas \\
\hline Total viviendas & 523.616 & 614.400 & $90.784(17 \%)$ & 100 \\
\hline Hogares & & & & 16 \\
\hline (viviendas principales) & 400.907 & 415.400 & $14.493(3,5 \%)$ & 84 \\
\hline Viviendas no principales & $122.709(23 \%)$ & $199.217(32 \%)$ & $76.508(62 \%)$ & 8 \\
\hline
\end{tabular}

Fuentes: INE y SADEI. Elaboración propia.

de que en algunas áreas ya son más las no principales que las principales. Este mayor peso de las viviendas no principales se debe a varios supuestos:

El gran auge de las viviendas secundarias, empleadas normalmente como vacacionales y/o finisemanales. Predominan, fundamentalmente en las áreas de mayor peso turístico; esto queda patente en la figura 10, donde se observa cómo en toda la costa asturiana, con la excepción de las dos ciudades (Avilés y Gijón) y Navia (un municipio de especialización industrial) dominan las viviendas secundarias dentro de las no principales. Del mismo modo, esto ocurre con numerosos municipios de montaña, especialmente cuando éstos se encuentran en espacios naturales protegidos, con gran renta de paisaje.

El despoblamiento de determinadas áreas, especialmente algunas de especialización agraria y antiguas zonas mineras, donde bien vía migración, bien vía mortalidad, llevan décadas perdiendo efectivos. En este caso, el incremento de las viviendas vacias no se debe al boom constructivo, sino a factores puramente demográficos.

Con cierta relación con el punto anterior, el cambio de residencia, frecuentemente de unas viejas a otras nuevas o por migraciones interiores, puede conllevar a una mayor presencia de viviendas vacías.

La especulación inmobiliaria, que emplea la vivienda como si de un activo financiero se tratase, esperando obtener beneficios derivados del importante incremento de precios registrado durante el boom y que, tras el estallido de la burbuja, con la bajada generalizada de precios y cierta retención del inmueble esperando que los precios se recuperen, se convierten en viviendas vacías.
Figura 9: Estimación del tipo de vivienda dominante en Asturias en 2009.

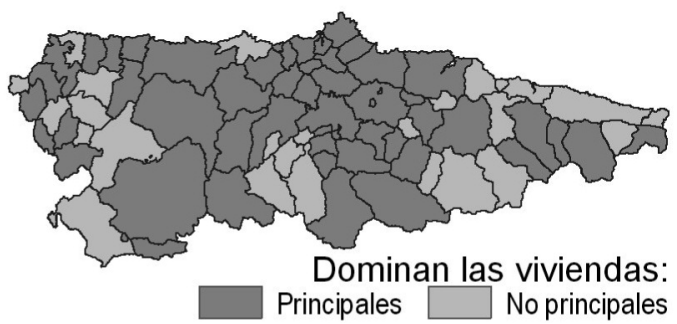

Fuente: SADEI e INE. Elaboración propia.

Figura 10: Estimación del tipo de vivienda no principal dominante en Asturias en 2009.

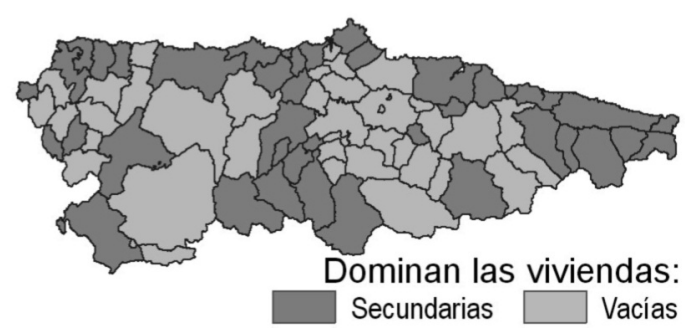

Fuente: SADEI e INE. Elaboración propia.

\subsection{Adecuación del parque residencial}

Uno de los quid de la cuestión es computar si el parque residencial heredado del periodo del boom se ajusta, más o

\footnotetext{
${ }^{10}$ Debido a la variedad de fuentes empleadas para esta tabla, cabe realizar varias aclaraciones:

Se han considerado los hogares como equivalentes a viviendas principales; por definición, vivienda principal es aquella utilizada toda o la mayor parte del año como residencia habitual de una o más personas; hogar es el conjunto de personas que residen en una misma vivienda. Las viviendas no principales son aquellas que no se emplean como residencia habitual. Existen varias clases, como las secundarias (estacionales, vacacionales o finisemanales), vacias y otras (ocupadas, por ejemplo, por negocios). Para este cuadro se estiman como el total de viviendas menos las principales.

Los datos de 2001 se corresponden al Censo de población y viviendas de 2001, del INE.

El total de viviendas de 2009 es el total estimado empleado durante todo el documento.

Los hogares de 2009 proceden de la Encuesta de condiciones de vida de 2009, del INE.
} 
menos, a las necesidades de la población asturiana o si, por el contrario, se encuentra sobredimensionado y hasta qué punto. Para calcularlo sería necesario estimar cuántas viviendas principales serian necesarias y añadirles las viviendas secundarias existentes, pues si bien éstas pueden generar debates sobre sostenibilidad, frivolidad, etc., de lo que no cabe duda es que se encuentran en uso.

Para calcular el número de viviendas principales necesarias es menester volver a emplear como sinónimo el término hogar para aplicar el concepto de la tasa de jefatura de hogar, un indicador procedente de los censos de población y vivienda y que se define como la proporción entre el número de personas de referencia ${ }^{10}$ de un grupo determinado ${ }^{11}$ y el total de población del mismo grupo.

Para facilitar su comprensión, siguiendo la perspectiva de este estudio, se puede considerar como un coeficiente que indica cuántas viviendas serían necesarias para un grupo determinado de población. Poniendo un ejemplo aclaratorio, si contásemos con una población de dos personas y éstas residiesen en una única vivienda, la tasa de jefatura de hogar sería de 0,5, es decir, una vivienda para cada dos personas. Los valores empleados son los extrapolados a partir de los censos y padrones existentes incluidos en el cuadro 2.

Tabla 2: Tasas de jefatura de hogar extrapoladas para Asturias, 2009.

\begin{tabular}{|l|l|}
\hline De 15 a 19 años & 0,024 \\
\hline De 20 a 24 años & 0,083 \\
\hline De 25 a 29 años & 0,188 \\
\hline De 30 a 34 años & 0,359 \\
\hline De 35 a 39 años & 0,469 \\
\hline De 40 a 44 años & 0,523 \\
\hline De 45 a 49 años & 0,526 \\
\hline De 50 a 54 años & 0,537 \\
\hline De 55 a 59 años & 0,529 \\
\hline De 60 a 64 años & 0,503 \\
\hline De 65 a 69 años & 0,452 \\
\hline De 70 a 74 años & 0,513 \\
\hline De 75 a 79 años & 0,576 \\
\hline De 80 a 84 años & 0,611 \\
\hline De 85 y más años & 0,567 \\
\hline
\end{tabular}

Fuentes: Censo de población y vivienda de 2001. SADEI. ORTEGA MONTEQUíN, M (2009).
Tras los cálculos señalados, se estima que Asturias contaría con un excedente de 104.667 viviendas, cifra que se corresponde con el 99,85\% de las viviendas levantadas durante el boom. No obstante, cabe aclarar que este indicador no señala que la práctica totalidad las viviendas levantadas durante este periodo se encuentren deshabitadas; cabe recordar que según el Ministerio de Fomento habría 12.000 viviendas nuevas terminadas sin vender, lo que se corresponde sólo con el 11\%; el 5\%, serían las que deberían encontrarse en el mercado para "permitir la libertad suficiente para que se puedan producir cambios de domicilio"12; el resto corresponderían a viviendas vacías en áreas en despoblamiento, o que no cumplen con los estándares requeridos para ser habitadas, retenidas dentro de un ya frustrado afán especulador basado en la compra-venta o incluso alguna que sencillamente parte de la vanagloria de poseer propiedades.

Atendiendo a cómo se distribuyen municipalmente estos excedentes, a priori parece directamente proporcional a la construcción de viviendas durante el boom; no obstante, comparando las figuras 11 y 12 se aprecia cómo la proporción del excedente de los mayores municipios es menor que el que manifestaba respecto de la construcción. Por otro lado, en los municipios de las antiguas áreas mineras destaca una proporción mayor del exceso de viviendas respecto de las levantadas durante el boom, efecto de la continua pérdida de población. De hecho, "en las cuencas mineras [...] aparece la mayor concentración de entidades deshabitadas de Asturias"13, lo que representa muy bien el fenómeno. Fuera del centro de la región, el ala oriental cuenta con un mayor excedente que el occidental, a igual que en la costa respecto del interior.

Más curioso resulta encontrar municipios donde no existe excedente de viviendas, sino un déficit teórico; de todos modos, en todos los casos se trata de municipios con un gran peso del sector agrario y del turismo y con un predominio importante de la vivienda secundaria, lo que viene a demostrar que el tamaño de los hogares en el medio rural tiende a ser mayor; además, dado que se trata de espacios que cuentan con una pérdida importante de población, parece que la corrección de este indicador irá por vía demográfica y no constructiva.

Además, atendiendo a la proporción relativa del excedente de viviendas, parece que con las excepciones de Oviedo, Siero y Parres los mayores excedentes se han dado en los municipios que pierden población y no donde más se ha construido.

\footnotetext{
${ }^{11}$ También denominado cabeza de familia. En los censos españoles se considera como tal al único miembro económicamente activo de un hogar o, si hay más de uno, el de mayor edad.

${ }^{12}$ En este caso se ha optado por emplear sólo grupos de edad quinquenales.

${ }^{13}$ DÍAZ FERNÁNDEZ, M; LLORENTE MARRÓN, M (2006).

${ }^{14}$ FERNÁNDEZ GARCIA, A (coord.) (2007).
} 
Figura 11: Excedente estimado de viviendas en Asturias en 2009.

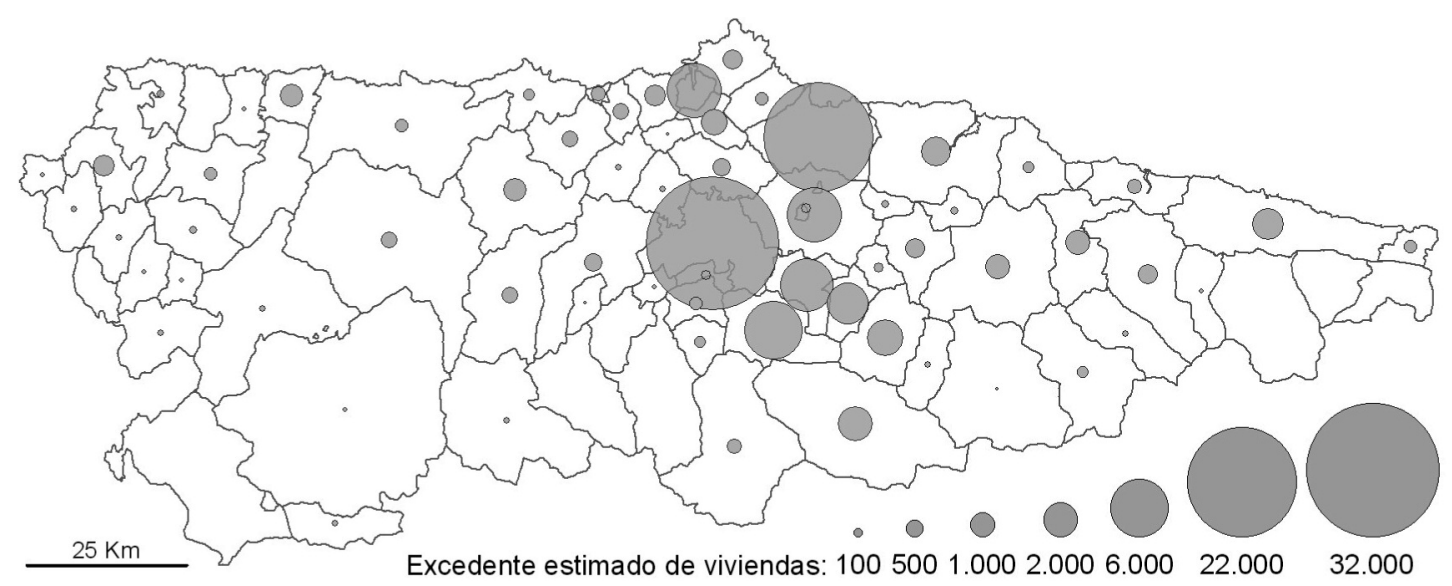

Fuente: Elaboración propia.

Figura 12: Excedente estimado relativo de viviendas en Asturias en 2009.

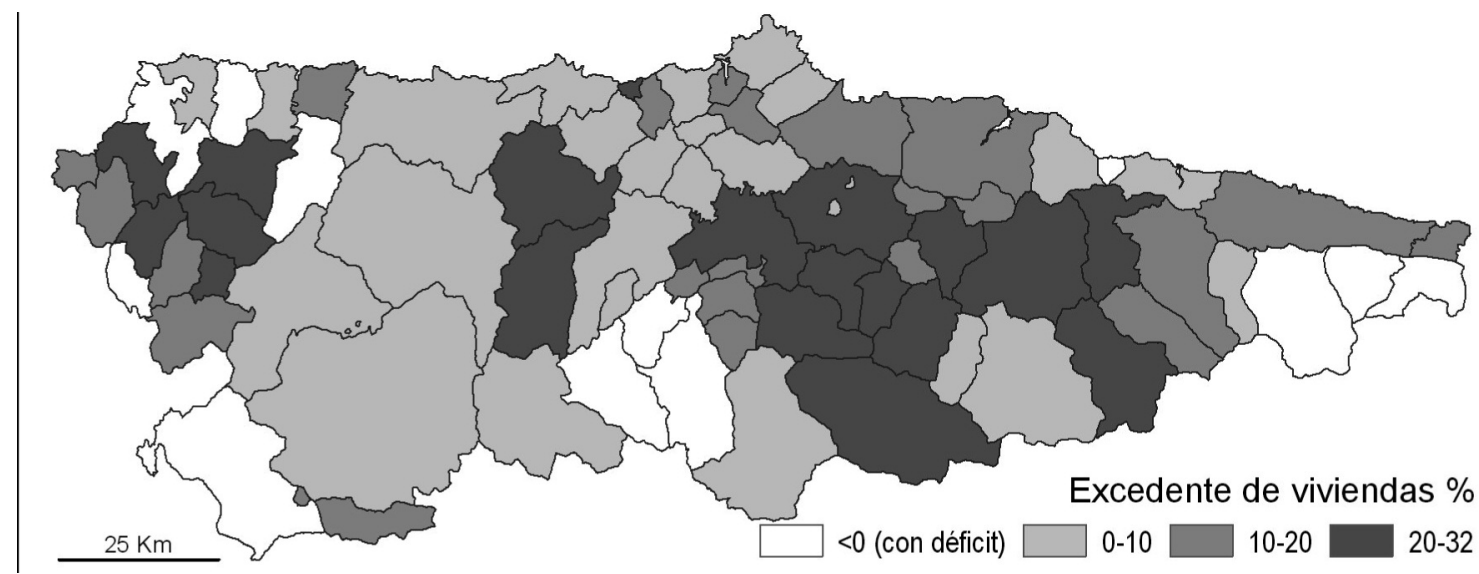

Fuente: Elaboración propia.

\subsection{El impacto físico: algunos ejemplos}

Lógicamente, un crecimiento del parque residencial como el comentado hasta ahora ha contado, por necesidad, con un destacado impacto físico en el territorio, con un crecimiento generalizado de aquellas entidades de población que acogieron un mayor número de viviendas, ya sea por medio de la expansión (habitual en los núcleos urbanos) o densificación (más frecuente en el medio rural). A continuación se expondrán de un modo breve algunos casos, a modo de ejemplo.

\subsubsection{El cierre perimetral de Oviedo y Gijón}

Oviedo y Gijón, las dos mayores ciudades de la región, han sumado entre las dos más de la mitad de las viviendas levantadas durante el periodo analizado, lo que ha supuesto una importante expansión de estas urbes.
Así, Oviedo se expandió en casi tres millones de metros cuadrados de un modo casi perimetral, pero con tres focos principales: el oeste, con la creación ex novo de barrios como La Florida o Les Campes (figura n 13); el sur, también con la creación del barrio de Montecerrao; pero, sobre todo, la expansión se dio hacia el norte (figura $n^{\circ} 14$ ), donde se urbanizaron más de dos millones de metros cuadrados, fundamentalmente apoyados en los barrios de Los Prados y La Corredoria, que pasó de ser un pequeño núcleo satélite de Oviedo que contaba con menos de 4.000 habitantes en 1996 a un barrio que mantiene continuidad con la ciudad y cuya población ya ascendía a 14.000 habitantes en 2009. Oviedo también conoció la reforma interior por medio de la operación denominada "Cinturón Verde", que suponía la supresión de las vías ferroviarias en la ciudad y de la que parte de los terrenos liberados tuvieron como destino la ocupación residencial. 
Figura 13: Los barrios del oeste de Oviedo en 1995 (izquierda) y 2009 (derecha).
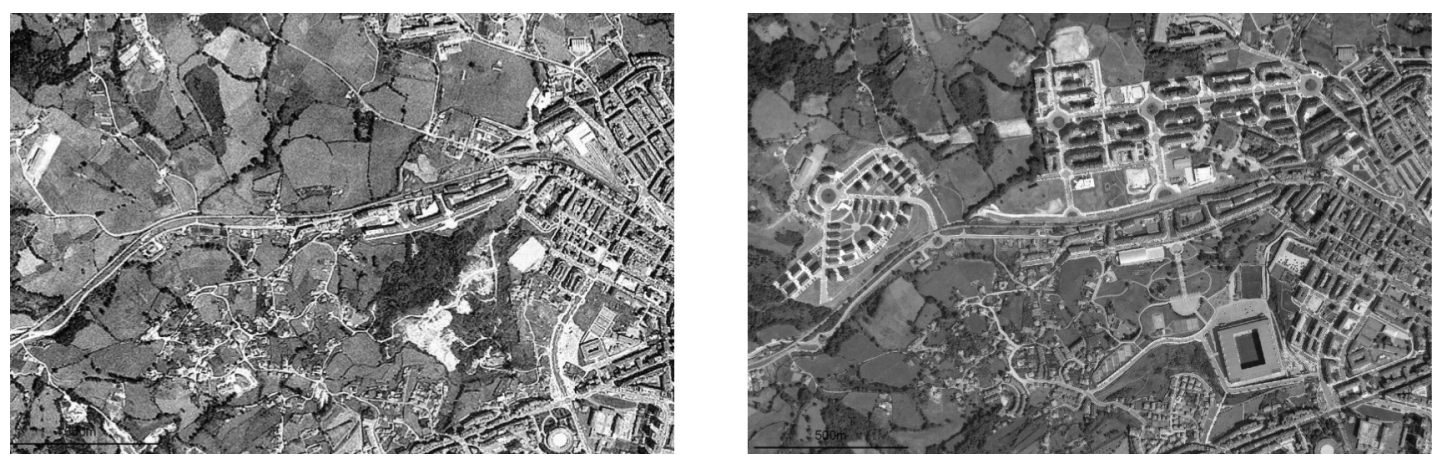

Fuente: Principado de Asturias (1995) y PNOA (2009).

Figura 14: Los barrios del norte de Oviedo en 1995 (izquierda) y 2009 (derecha).
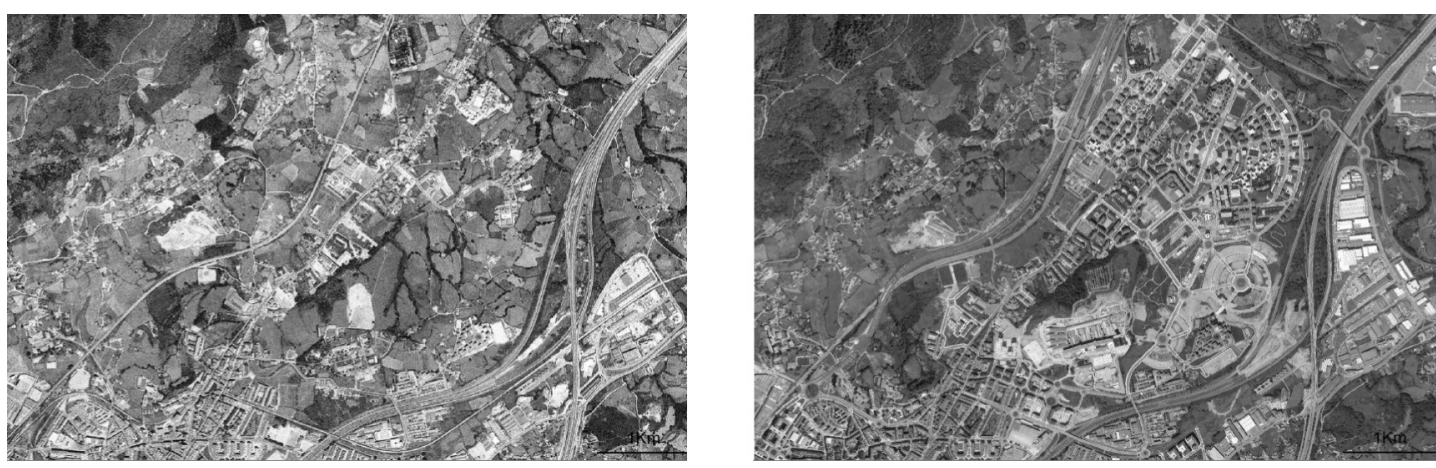

Fuente Principado de Asturias (1995) y PNOA (2009).

En el caso de Gijón el crecimiento fue menor, con una expansión de algo más de dos millones de metros cuadrados. No obstante, su comportamiento ha sido el propio de una ciudad medieval: la apertura de la autovía A-8 prácticamente a principios del boom hizo las funciones de muraIla, concentrándose la expansión perimetral de la ciudad en lo que se podría denominar el espacio de "intramuros". La única excepción a este cometido son los barrios del oeste, donde la autovía que conectará la existente con el puerto de El Musel aún no ha sido ejecutada.

Los principales crecimientos se dieron en el sur y en el este de la ciudad (figuras $n^{\circ} 15$ y 16), si bien con orientaciones diferenciadas, pues mientras en el sur las operaciones de vivienda protegida contaron con un peso específico, el este se destinó a clases más pudientes económicamente.

Figura 15: Los barrios del sur de Gijón en 1995 (izquierda) y 2009 (derecha).
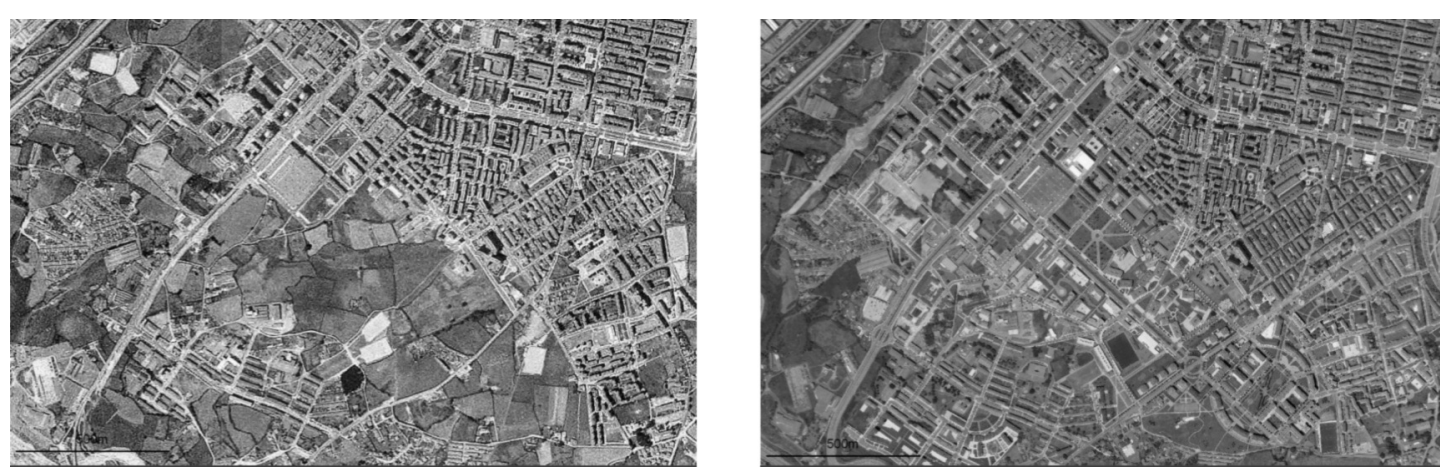

Fuente Principado de Asturias (1995) y PNOA (2009). 
Figura 16: Los barrios del este de Gijón en 1995 (izquierda) y 2009 (derecha).

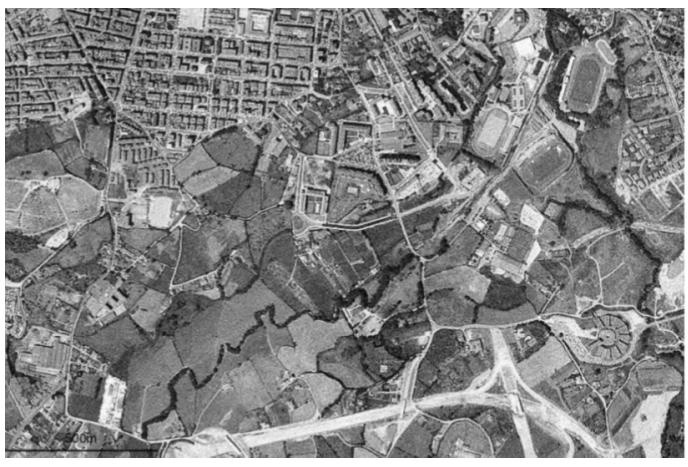

Fuente: Principado de Asturias (1995) y PNOA (2009).

\subsubsection{Las viviendas póstumas: el boom de la vivienda protegida}

Como se ha citado, durante el boom inmobiliario, la construcción de viviendas protegidas se redujo de un modo muy importante, tanto en términos absolutos como relativos. Sin embargo en 2009 la cifra de viviendas protegidas iniciadas se dispara respecto a la de años anteriores, siendo la mayor de los veinte años de que se disponen datos. Además, el hecho de que éstas supusiesen más de la mitad de las viviendas iniciadas dicho año lleva a concluir que se trató de un boom de la vivienda protegida y que las administraciones mantuvieron durante un tiempo el sector.

Cabe citar, no obstante, que la mayor parte de estas viviendas se plantearon durante el propio boom, pero lo dilatado de los plazos, especialmente los administrativos, conllevaron que no fuese hasta entonces el inicio de las obras.

La mayor parte de las viviendas aludidas se deben a dos grandes operaciones, una en Oviedo y otra en Gijón. Así, la primera gran operación en ejecutarse es la ovetense Prado de Vega (figura $n^{\circ} 17$ ), sita entre el nuevo HUCA (Hospital Universitario Central de Asturias) y La Corredoria. Su urbanización se inició en 2007, por lo que las viviendas no pudieron iniciarse hasta uno o dos años después. En conjunto, la operación levantaria un total de 3.400 viviendas, siendo el 60\% protegidas $^{15}$.

La otra es la que se ha dado en Roces, en Gijón (figura $n^{\circ} 18$ ), con un total de 3.700 viviendas, el $82 \%$ protegidas $^{16}$. Siguiendo la analogía de puntos anteriores y considerando la Autovía del Cantábrico como la muralla de la ciudad, empleando términos de origen medieval se trataría de un arrabal; en efecto, la nueva área residencial de Roces "salta" la autovía que había definido la importante expansión del boom y donde aún quedan espacios vacantes. De hecho, el efecto barrera no lo produce sólo la autovía señalada, sino también la Minera (AS-I), asi como el polígono industrial del Roces,

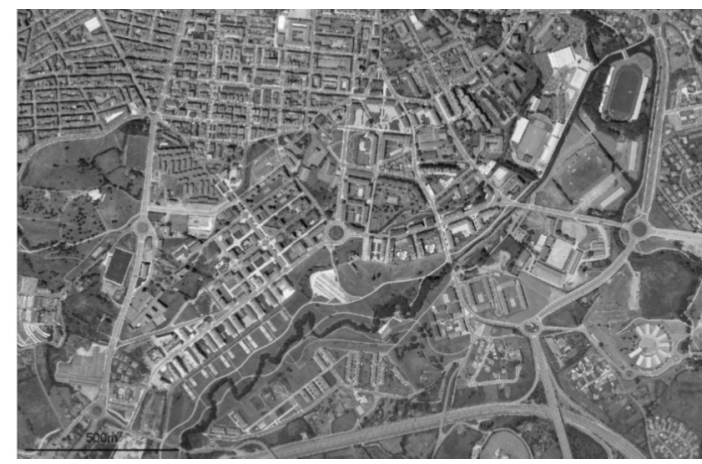

Figura 17: Prado de Vega, Oviedo.

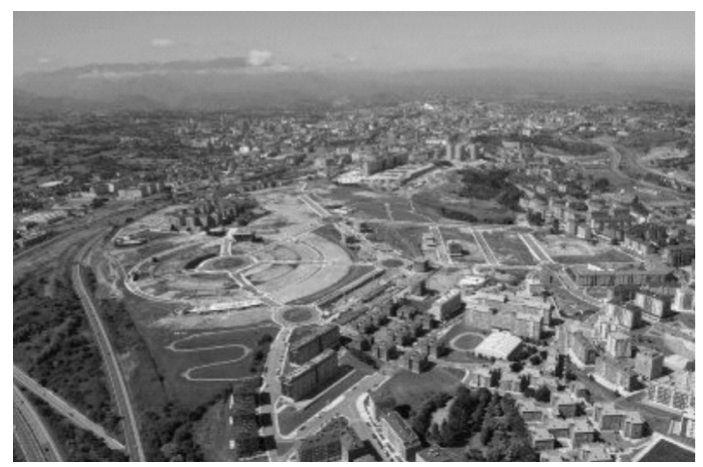

Fuente: www.sogepsa.com

Figura 18: Nueva área residencial de Roces, Gijón.

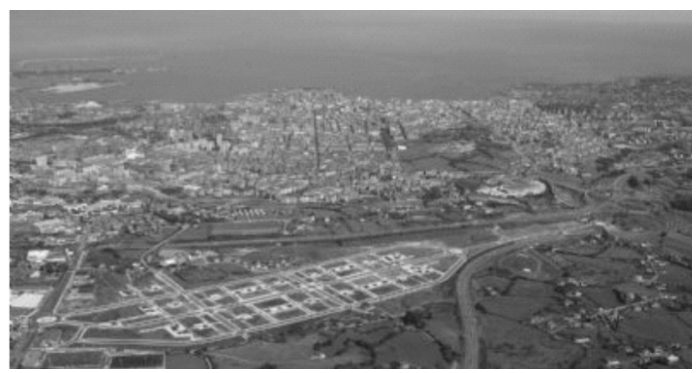

Fuente: www.sogepsa.com

Figura 19: Arriondas Norte, Parres.

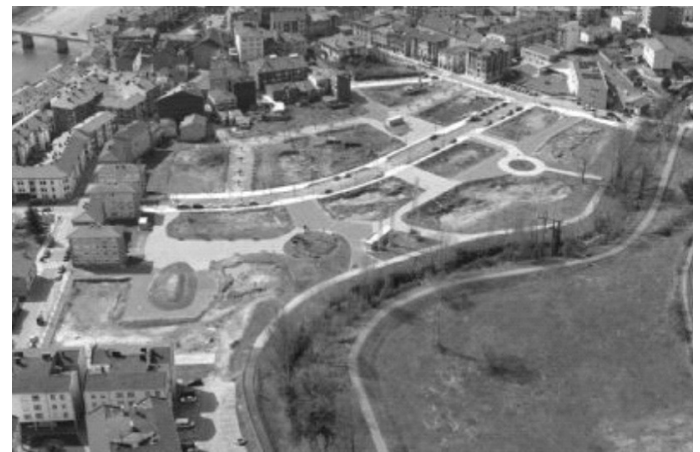

Fuente: www.sogepsa.com 
con el que linda por el oeste, lo que hace que el espacio se encuentre, hasta cierto punto, mal comunicado, con accesos sólo por sus extremos.

Fuera de las dos mayores ciudades también existe producción de viviendas protegidas, si bien sus volúmenes distan considerablemente. Al menos desde un punto de cifras absolutas, pues en términos relativos la mayor operación que se conoce se da en Arriondas (Parres), en una operación denominada Arriondas Norte (figura $n^{\circ} 19$ ), pues ha iniciado la construcción de 445 viviendas ${ }^{17}$, lo que supondría más del 10\% del parque residencial de este municipio.

\subsubsection{La ciudad difusa en el área central}

El centro de la región, en el espacio que queda entre las tres mayores ciudades de la región (Gijón, Oviedo y Avilés) se ha dado un "salpicado" de usos urbanos (ya sean residenciales, industriales, comerciales, etc.) que configura lo que se viene denominando como ciudad difusa. En términos residenciales, el espacio con una mayor intensidad constructiva ha sido el espacio sito al norte y este de la ciudad de Oviedo. Se pueden distinguir tres modos diferentes de ocupación residencial de este espacio:

- Las villas principales y demás entidades urbanas de vivienda colectiva dominante: incluyendo La Corredoria y Colloto, que actualmente ya suponen apéndices de Oviedo, habría nueve núcleos de población que en 2009 contaban con más de tres mil habitantes. Y, en todos ellos, su crecimiento demográfico ha sido más que sensible desde 1996, superior al 55\% en su conjunto, lo que ha conllevado, a su vez, una gran expansión de su parque de viviendas.

- Las urbanizaciones residenciales: tendentes, sobre todo hacia la residencia unifamiliar, si bien en los últimos años han aparecido ejemplos de viviendas colectivas de baja densidad. El caso más destacado es el de La Fresneda (figura n²0), iniciado en los años 80 pero con gran expansión en los últimos años; además se pueden citar otras como Soto de Llanera, Meres, Los Vallones, etc.

- Los núcleos rurales, donde se han entremezclado las piezas tradicionales del campo con una cada vez mayor proporción de construcciones urbanas, con cierta frecuencia con una anómala promiscuidad de usos.

\subsubsection{Las villas capitales de municipio}

Es donde mayores casuísticas se dan, siendo cada caso particular. De todos modos, cabe citar que la mayor parte de los crecimientos bien se muestran análogos a los señalados para el área central, siempre que se muestren próximos a una de estas ciudades, bien se trata de espacios fundamentalmente turísticos en los que la segunda vivienda ha primado.

De todos modos, cabe mencionar que éstas han sido receptoras de algunos de los mayores excesos, al menos en términos relativos y, en ocasiones, morfológicos. Así, operaciones de no demasiadas viviendas pueden suponer un crecimiento relativo exagerado, y en determinadas áreas rurales el diseño implantado no ha sido el más adecuado.

\subsubsection{Los núcleos rurales}

El hecho de que existan más de cinco mil núcleos rurales en Asturias hace que en éstos se hayan dado todas las casuísticas posibles en lo que al boom inmobiliario se refiere. Así, se puede distinguir entre:

- Núcleos de áreas turísticas costeras: habitualmente muy bien comunicados y de rápido acceso a villas, equipamientos, ocio, etc., son los que mayor intensidad constructiva han vivido. Su crecimiento en ocasiones se traduce en un incremento de la densidad de

Figura 20: Área de Lugones y La Fresneda (Siero) en 1995 (izquierda) y 2009 (derecha).
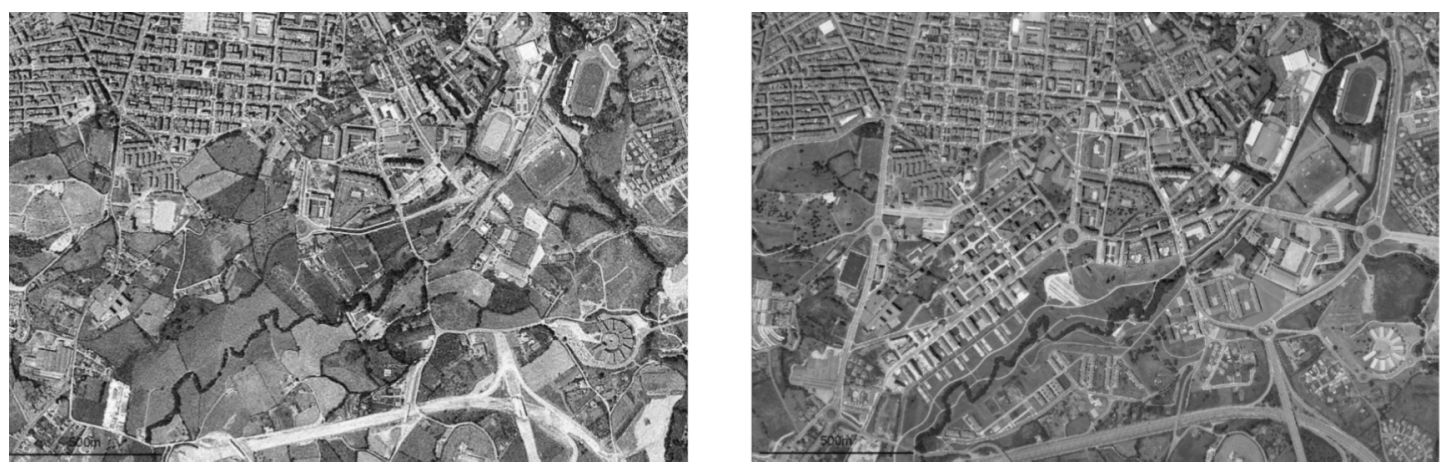

Fuente: Principado de Asturias (1995) y PNOA (2009). 
los mismos, al ocupar piezas agrarias intersticiales al espacio construido anterior, fenómeno perceptible en el ejemplo de la figura 21.

Pero esto también ha conllevado la introducción de nuevas tipologías constructivas dentro de estos núcleos, con un cariz más próximo al urbano propio de ciudades jardín, pues las piezas agrarias propias de estos espacios no son necesarias para el nuevo usuario. De hecho, ha sido relativamente frecuente la presencia de micro-urbanizaciones de seis chalés (reparcelación máxima permitida), cuyo impacto en el paisaje resulta, hasta cierto punto, acusado. No obstante, cabe señalar que la tendencia más habitual ha sido la de levantar imitaciones adaptadas (sobre todo en volumen) de las presentes en cada núcleo.

Figura 21: Pandu (Ribadesella), un núcleo rural de importante expansión.

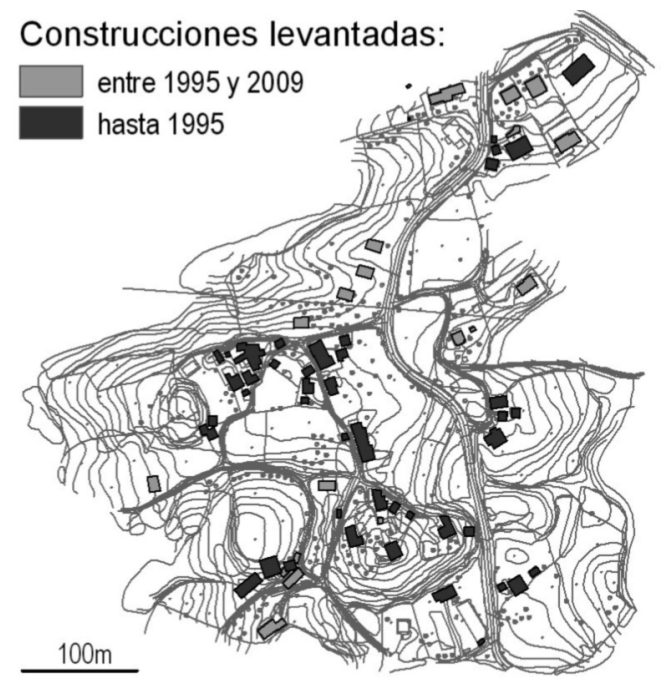

Fuentes: Ortofotos de los diferentes años. Elaboración propia.

- Núcleos en espacios naturales protegidos: que, en contraposición a los anteriores, pueden recibir el apelativo "de montaña", si bien la mayor parte se circunscriben a espacios incluidos en diferentes figuras de protección. Éstos cuentan con peores comunicaciones y menor accesibilidad a equipamientos urbanos, pero tienen capacidad para vender paisajes sobresalientes. Sobre ellos el crecimiento del parque residencial ha sido muy diferente, pues han primado las rehabilitaciones y las reconstrucciones (edificar sobre terrenos anteriormente edificados) sobre la expansión.

El Parque Natural de Redes puede ser considerado como todo un ejemplo en la materia, alcanzándose una gran integración del espacio construido de varios núcleos, casos, por ejemplo, de Bezanes (Caso) o Soto de Agues (Sobrescobio). Este último ha contado con una regeneración importante de su tejido constructivo, así como ha añadido piezas necesarias para acoger el volumen de visitas que recibe, casos del aparcamiento o de los albergues. El Parque Natural de Somiedo, también cuenta con ejemplos dignos de mención, como puede ser el ejemplo de Caunedo, que ha sido el primer núcleo de turismo rural de Asturias, figura que básicamente se enfoca a ofrecer una buena oferta en alojamientos y hostelería reconstruyendo y manteniendo el patrimonio edificado heredado. Con ello, la presencia de casas de aldea, apartamentos rurales y negocios hosteleros copan buena parte del pueblo.

-El resto de entes rurales, donde puede efectuarse una división entre aquellos que mantienen la actividad agraria y los que están en vías de abandono, si bien su diferencia más marcada es su estado de conservación. En ninguno de los dos casos se puede aseverar que haya existido expansión residencial alguna, si bien en el caso de los núcleos agrarios puede aparecer, puntualmente, alguna construcción reciente; de hecho, gran parte de las nuevas construcciones no son viviendas, sino piezas para la explotación agropecuaria (si bien es cada vez más habitual que se emplacen fuera de los núcleos).

De todos modos, los núcleos agrarios mantienen el caserío tradicional, así como las funciones propias del espacio rural adaptadas a la producción actual. Por contra, los núcleos en vías de abandono suelen ser los de menor tamaño y más aislados, donde la degradación y la amenaza de ruina son sus principales caracteres.

\section{CUESTIONES SOBRE LOS ESCENARIOS FUTUROS}

Lo visto hasta ahora permite tener una perspectiva y mensurar los efectos que ha tenido el boom inmobiliario en Asturias. No obstante, más que obtenerse conclusiones se plantean cuantiosas cuestiones. A continuación se expresarán algunas de ellas apuntando alguna reflexión al respecto.

Por la dinámica demográfica asturiana, ¿es posible reactivar el mercado de la vivienda? Considerando que Asturias es la Comunidad Autónoma demográficamente más vieja de España, lo que supone una baja natalidad y una elevada mortalidad, además del vacío de nacimientos de los años 90 del siglo $\mathrm{XX}$, todo apunta a que el mercado inmobiliario, asi como el resto de factores económicos y sociales, tendría una gran dependencia de mantener saldos migratorios positivos que, cuanto menos palien la pérdida de población por factores naturales.

¿Se ajusta la oferta a la futura demanda? El hecho de que exista un stock de gran variedad de viviendas conlleva que gran parte estaría cubierta; pero no toda, pues siempre hay casuísticas especiales que no se ajustan a lo disponible. 
Quizás el caso más ejemplificante sea el querer una casa "justo en esta parcela", muy habitual en el medio rural.

Que haya un excedente de viviendas, ¿implica que éstas estén en el mercado? No; de hecho, una de las grandes preguntas que se hacian las autoridades públicas durante el propio boom era cómo hacer que las viviendas vacías entrasen en el mercado inmobiliario (especialmente en el del alquiler). $Y$ es que la vivienda se ha convertido, desde mucho antes del boom, en un objeto de deseo similar al que antaño tuvieron las tierras rústicas, muchas veces más próximo a la propia vanagloria que a una situación real.

¿Cómo actuarán los poderes públicos en esta materia? Sin duda alguna, desde la esfera política y en la aplicación del desarrollo (o a lo que habitualmente ha recibido dicho término), las "cuentas de la lechera" son fundamentales. Así se están llevando a cabo una serie de inversiones (portuarias, logísticas, industriales, culturales, etc.) cuyo objetivo sería el crecimiento económico, para lo que haría falta mano de obra y ésta necesitaría de un sitio donde vivir. Por ello, desde esta perspectiva siempre serán necesarias nuevas viviendas, línea que se mantiene ya en la actualidad, pues siguen planteándose y proyectándose nuevas operaciones de vivienda protegida. Ahora bien, todas ellas requerirán que se cumplan los objetivos económicos previos para que alcancen su ocupación.

¿Se seguirá manteniendo una expansión de ciudades y villas? Probablemente sí, pero en una medida ridícula en comparación con la experimentada en las últimas décadas. Una de las líneas más habituales en la teoria urbanística indica que en las ciudades occidentales, el futuro de las mismas pasa por la regeneración de los espacios existentes y no por su expansión. Y, enlazado a la respuesta anterior, todo apunta a que ésta sea la tendencia.

¿Cómo será el comportamiento de las áreas rurales? Por un lado, el espacio rural se ve obligado a renovar gran parte de su población, debido a su elevada edad media. Así, por un lado, habría que reemplazar la mano de obra del campo, que si bien ya cuenta con pocos efectivos no parece que deba retrotraerse más. Por otro lado, todo apunta a que vaya a recibir población jubilada de las ciudades, si bien se trataría más bien de habitantes estacionales, especialmente estivales. No obstante, parece que estas dos líneas no serán suficientes como para reemplazar a la ya escasa población rural. Además, siguiendo las propias tendencias actuales, puede haber una importante diferenciación entre los núcleos rurales bien comunicados y próximos a centros urbanos respecto de otros con peor localización, lo que derivaría en una dicotomía de pueblos cuidados por población urbana y un número creciente de entidades deshabitadas. De cara a la construcción, las adaptaciones a los requisitos de población urbana, así como a las nuevas condiciones de producción agraria, serían las vías sobre las que podría mantenerse algo de actividad.
Los espacios históricamente mineros, ¿seguirán en vías de abandono o habrá un cambio de sentido? Los espacios mineros cuentan con un importante problema de imagen, pues a pesar de haber contado en las últimas décadas con cuantiosas inversiones continúan perdiendo población. Además, esto no deja de ser una contradicción, pues en los últimos años (al menos en los previos a la actual crisis) han ganado empleos; sin embargo, parece que las buenas comunicaciones de que se han dotado han servido para que los trabajadores de estas áreas tiendan a residir fuera de ellas, preferentemente en Oviedo y Gijón. Su única solución sería lograr un cambio de imagen y que ésta llegase a potenciales residentes; de no ser así seguirá acumulando entidades deshabitadas.

Como corolario final, debe mencionarse que en Asturias, España y Europa (que son inclusivos) existe la contradicción de que si bien habria mucho que cambiar, está todo hecho. En términos de viviendas, se podría aseverar que hay más que de sobra, pero que no se van a ajustar todas a las demandas futuras y otras ni siquiera van a entrar en el mercado, por lo que el sector se va a ralentizar, incluso a hibernar, pero no a desaparecer. Sin embargo, dadas las condiciones demográficas de Asturias, para que esto se produzca sería necesaria la aportación de inmigrantes, pues su movimiento natural resulta a todas luces negativo. No obstante, para que esta migración se efectúe sería necesario que el desarrollo económico demandase mano de obra en cantidad suficiente.

\section{DOCUMENTACIÓN Y BIBLIOGRAFÍA}

BURRIEL DE ORUETA, E (2008): "La década prodigiosa del urbanismo español (1997-2006)", en Scripta Nova, revista electrónica de Geografía y Ciencias Sociales 270.

CALDERÓN, B (2004): "La ciudad del todo urbanizable: estrategias del sector inmobiliario y nuevas e insostenibles formas de urbanización", en Ciudades 8, pp. 135-155.

DÍAZ FERNÁNDEZ, M; LLORENTE MARRÓN, M (2006): 2005, un análisis del mercado de la vivienda en Asturias, Consejería de Vivienda y Bienestar Social del Principado de Asturias.

FERNÁNDEZ GARCÍA, A; ALONSO IBÁÑNEZ, R (coord.) (2007): El medio rural y la difusión urbana, Oviedo, KRK Ediciones.

FERNÁNDEZ GARCÍA, A (coord.) (2007): Población, administración y territorio en Asturias, Oviedo, CES Asturias.

FERNÁNDEZ GARCÍA, A; ALONSO IBÁÑEZ, R (coord.) (2008): Los nuevos usos del suelo en el litoral asturiano, Oviedo, KRK.

FUENTES CASTRO, D (2009): "Una nota sobre el exceso de oferta de viviendas y la duración del ajuste del sector", en Boletín ICE Económico2.958, pp. 15-24.

GAJA I DÍAZ, F (2008): "El tsunami urbanizador en el litoral mediterráneo. El ciclo de la hiperproducción inmobiliaria 1996-2006", en Scripta Nova, revista electrónica de Geografía y Ciencias Sociales 270.

GILI I FERNÁNDEZ, M (2003): "Las viviendas de segunda residencia, ¿ocio o negocio?", en Scripta Nova, revista electrónica de Geografía y Ciencias Sociales 146.

INE (Instituto Nacional de Estadística), publicaciones en Web (www.ine.es).

Ministerio de Fomento (que asume los contenidos del desaparecido de 
Vivienda), publicaciones en Web (www.fomento.es).

ORTEGA MONTEQUÍN, M (2009): Previsión de la dinámica inmobiliaria en Gijón 2009-2020 (inédito).

PNOA (2009): Ortofoto digital 1:5.000 del Plan Nacional de Ortofotagraía Aérea, CNIG.

RODRÍGUEZ LÓPEZ, J (2008): "La situación del mercado de viviendas en España", en Boletín ICE Económico2.951, pp. 11-23.

PRINCIPADO DE ASTURIAS (1995): Ortofotografías del Principado de Asturias 1:25.000, Principado de Asturias.

SADEI (Sociedad Asturiana de Estudios Económicos e Industriales), publicaciones en Web (www.sadei.es).
SOGEPSA (Sociedad Mixta de Gestión y Promoción del Suelo, S.A), página web http://www.sogepsa.com, consultada en noviembre de 2011.

SERRANO, J (2004): "Expansión del parque inmobiliario en España. Algunas reflexiones desde la perspectiva territorial", en Boletín ICE Económico2.793, pp. 11-30.

THE HAGUE: MINISTRY OF THE INTERIOR AND KINGDOM RELATIONS (2010): Housing Statistics in the European Union, OTB Research Institute for the Built Environment.

TORTELLA, G (2008): "Crisis, ciclos e historia", en el diario El País del 25 de septiembre de 2008. 